\title{
IMPACTO DA CIRURGIA ORTOGNÁTICA SOBRE A QUALIDADE DE VIDA DE PACIENTES ATENDIDOS NO SERVIÇO DA UNIVERSIDADE FEDERAL DO PARANÁ
}

Paola CORSO, Rafaela SCARIOT, Fábio Augusto Coelho OLIVEIRA, Luiza NASCIMENTO, Nelson REBELLATO

A qualidade de vida vem sendo discutida e estudada cada vez mais nos últimos anos quando falamos em saúde, abrindo um leque para o estudo dos impactos que ela pode vir a trazer. A preocupação com a técnica nos procedimentos odontológicos começa a ser percebida de um novo ponto de vista, com maior enfoque no ser humano como um todo. Tendo em mente uma nova concepção de saúde, o "The Oral Health Impact Profile" (OHIP) é usado como intrumento para avaliar o impacto de problemas bucais no indivíduo, abrangendo as dimensões física, psicológica e social da vida diária. O OHIP14, versão resumida do OHIP, foi publicado por Slade em 1997. Este estudo, realizado na Universidade Federal do Paraná, avaliou o impacto na qualidade de vida dos pacientes submetidos a cirurgia ortognática a partir do uso desse questionário. $O$ estudo mostrou um impacto negativo na qualidade de vida maior nos indivíduos que apresentam deformidades dentofaciais do que naqueles que não apresentam.

Palavras-chave: Qualidade de Vida; Cirurgia Ortognática; Saúde 